1 Universidade de Pernambuco (UPE) - Recife (PE), Brasil.

Orcid: https://orcid org/0000-0001-64156977

leonardo.carnut@gmail.com

2 Universidade de São Paulo (USP) - São Paulo (SP), Brasil.

Orcid: https://orcid org/0000-0003-47696896

pcnarvai@usp.br

\section{Controle social e avaliação de desempenho de sistemas de saúde em tempos de webcontrole}

\author{
Social control and performance evaluation of health systems in times \\ of webcontrol
}

Leonardo Carnut', Paulo Capel Narvai²

DOI: $10.1590 / 0103-1104201811817$

RESUMO Este ensaio teve como objetivo indagar sobre a forma como, no Brasil, o controle público ('controle social') está sendo feito, especialmente na contemporaneidade, quando a internet entra como um elemento a tornar ainda mais complexos os caminhos para o efetivo exercício do controle do desempenho das políticas de saúde. Para tanto, abordam-se as características do desempenho desse tipo de controle público nas ciências administrativas e sua influência nos processos de avaliação em saúde, a complexidade implicada na opção de tomar os 'sistemas de saúde' como 'objetos' da avaliação de desempenho e, ainda, a capacidade do sujeito contemporâneo de participar desse tipo de 'controle social' em sua forma virtual. Uma possibilidade sugerida para esta participação, sem necessariamente se institucionalizar, pode ter como ponto de partida a elaboração da opinião coletiva oriunda da captura e do processamento das percepções individuais disponibilizadas sobre os desempenhos, em todos os sítios eletrônicos na 'web'.

PALAVRAS-CHAVe Sistema Único de Saúde. Democracia. Participação da comunidade. Sociologia. Avaliação em saúde.

ABSTRACT This essay aimed at inquiring how, in Brazil, public control ('social control') is being done, especially in contemporaneity, when the internet enters as an element to make even more complex the ways to the effective exercise of the control of health policy performance. For this purpose, the characteristics of performance of this kind of public control in administrative sciences and their influence on health assessment processes were addressed, the complexity involved in the option of taking 'health systems' as 'objects' of performance evaluation and, still, the ability of the contemporary subject to participate in 'social control' in its virtual form. A suggested possibility for this participation, without necessarily being institutionalized, may have as its starting point the elaboration of the collective opinion derived from the capture and processing of the individual perceptions made available on the performances, in all the electronic sites in the 'web'.

KEYWORDS Unified Health System. Democracy. Community participation. Sociology. Health evaluation. 


\section{Introdução}

No contexto histórico das reformas institucionais que ganharam curso no Brasil, na esteira do movimento Diretas Já, que pôs fim politicamente à ditadura civil-militar instalada com o golpe de Estado de 1964, a expressão 'controle social' emergiu no âmbito da Reforma Sanitária e se consolidou, no jargão popular, após a criação do Sistema Único de Saúde (SUS) pela Constituição de 1988 (CF-88).

Os anseios por colocar as políticas públicas sob o controle democrático da população levaram à inscrição na Carta Magna de 1988 do princípio doutrinário da 'Participação da Comunidade' nos assuntos atinentes ao SUS, em todos os entes federativos. A Lei Federal $\mathrm{n}^{\circ} 8.142 / 1990$ regulamentou as formas dessa participação, por meio de conferências e conselhos de saúde, em níveis nacional, estadual e municipal.

A essa forma de participação, conselheiros de saúde, sobretudo, passaram a denominar 'controle social', com a perspectiva de afirmar que não bastava que houvesse controle pelos três poderes da República, tal como é a missão dos poderes Legislativo e Judiciário, e dos órgãos de controle do próprio poder Executivo (de auditoria e controle, por exemplo), mas que, ademais esses mecanismos rotineiros, houvesse também, institucionalizado, o controle por parte de entidades e movimentos variados que, no cotidiano da vida social, expressam interesses populares, também reconhecidos como 'sociais'.

O uso acabou por consagrar a expressão 'controle social' com a acepção de exercício do controle, pela sociedade civil, sobre as ações do Estado, notadamente as políticas públicas, não obstante o amplo reconhecimento no âmbito das ciências sociais de que a expressão 'controle social' tem o papel de se referir ao controle que o Poder, e de modo contemporâneo, o Estado, realiza sobre o conjunto da sociedade como instrumento de coerção social, sempre acompanhado de mecanismos persuasórios destinados ao convencimento de todos sobre a inevitabilidade da medida coercitiva, e de que o que se faz é feito em benefício e para a proteção de todos. A despeito, portanto, do fato de que antes da emergência histórica das formas contemporâneas de Estado, as práticas de 'controle social', como expressões de poder, sejam identificadas e reconhecidas na maioria das formações sociais ${ }^{2}$.

No Brasil, o período histórico que se seguiu à promulgação da $\mathrm{CF}-88$ produziu um importante esvaziamento do impulso reformista das lutas democráticas pelo fim da ditadura, conforme ampla literatura que registra o progressivo fenecimento do SUS e as dificuldades para a consolidação do sistema de seguridade social do qual é parte, bem como outras políticas públicas orientadas à garantia de direitos sociais, como a educação e a habitação popular, para citar apenas alguns setores.

Em tal cenário, oposto ao idealizado por lideranças políticas identificadas com os interesses populares ('sociais'), a 'Participação da Comunidade' prevista na CF-88 vem sendo apenas tolerada, por exigência legal, mas é sistematicamente alijada de qualquer tipo de protagonismo nas decisões que dizem respeito à saúde dos brasileiros - e não somente do SUS. Além disto, muitos conselhos de saúde são manietados, vítimas de nepotismo e da integração, em seus quadros, de conselheiros ineptos, urdidos pelo poder Executivo. Restam, destas deformações, apenas aparências de protagonismo por representantes da sociedade civil, falsificando-se o Estado Democrático de Direito ${ }^{3}$.

Não obstante, a tese da 'Sociedade Civil que controla a Administração Pública' defendida pela saúde coletiva, em uma nova roupagem, também tem sido defendida pelo pensamento administrativo pós-burocráti$\mathrm{CO}^{4}$ (que basicamente aposta na 'contingência' dos ambientes), especialmente aquele receitado pelo que se vem denominando 'gerencialismo'5. Contudo, são escassas as análises, no Brasil e em outros países, sobre o sujeito contemporâneo que compõe a 
sociedade civil, raramente indagando-se sobre a capacidade que ele teria para efetivamente controlar as ações do Estado.

A própria acepção de 'sociedade civil', a depender do autor em que se afilia a análise, já enseja debates acadêmicos profundos ${ }^{6}$. Mesmo sob esta intensa pluralidade, há algum consenso de que é na esfera da sociedade civil que ocorre a formação do poder ideológico, e que este é expresso (tanto em forma como em conteúdo) na versão de 'controle social' formulada por lideranças sociais, sanitaristas e gestores adeptos do 'gerencialismo'.

Admite-se que tal poder ideológico seja, em parte, produto da opinião coletiva dos sujeitos interessados em debates públicos, podendo ser compreendido como a expressão pública da gradação existente entre consenso-dissenso a respeito das instituições (e seus atos), transmitidas através da imprensa, do rádio, da televisão e contemporaneamente, através das redes sociais?.

É possível afirmar, portanto, que, neste tempo social no qual o debate sobre o direito à saúde vem ganhando relevo, haja um conteúdo elaborado pelos sujeitos interessados no tema do 'Desempenho das Políticas Públicas de Saúde' como forma de efetivação deste direito. Em outras palavras, é relevante conhecer a qualidade do discurso destes sujeitos que compõem o conteúdo do 'controle social', tal como se efetiva contemporaneamente no Brasil.

A análise do 'controle social', tal como se dá concretamente no País, no contexto histórico da 'Sociedade da Informação' aberta pelos avanços na tecnologia de informação e, sobretudo, com o advento da rede mundial de computadores (internet; 'web'), e, ainda, com sua popularização a partir dos anos 1990, requer considerar que um novo sujeito 'produtor-produzido' 'de/pelo contemporâneo' se faz presente.

Há, portanto, mudanças impostas nos processos e na qualidade do 'controle social', notadamente a partir das décadas iniciais do século XXI. Abre-se, então, aos diferentes segmentos, grupos e até mesmo classes sociais, um cenário em que aportes de dados e informações, sequer cogitados há alguns anos, alteram profundamente a capacidade de julgar as decisões e as atividades realizadas pela administração pública à luz da reconfiguração do Estado brasileiro.

Fundamental no debate sobre a capacidade desse sujeito da sociedade civil de alterar a qualidade do 'controle social' sobre as políticas públicas é o modo como são acessados e utilizados dados e informações. No século XXI, a informação aparece a serviço de uma 'nova ordem' que a subsuma à racionalidade econômica neoliberal fundamentalmente através do excesso de informação que se transforma em ruído ${ }^{8}$, e na instantaneidade da informação por oposição ao seu processamento histórico 9 .

Ademais, a ausência da intersubjetividade na formulação das opiniões individuais e na construção da opinião coletiva tende a gerar representações sociais que massificam ideias cada vez menos expostas ao contra-argumento. Isto torna a informação um reflexo de quem domina os meios de comunicação em massa, fazendo com que certos enunciados se transformem em ideologias ${ }^{\mathbf{1 0}}$.

É nesse cenário que a questão da natureza do sujeito contemporâneo ${ }^{11,12}$ e seu (des) interesse pelo debate público traz à baila o impasse a respeito do 'adequado controle' da sociedade civil sobre as formas de organização das políticas públicas, no que se convencionou denominar 'Estado gerencial'13.

Não é demasiado reiterar, com Touraine $\mathbf{1 4}^{\mathbf{4}}$, que o sujeito ‘democrático' é refém da aguda complexificação das estruturas sociais modernas. Logo, o cenário social lhe aparece inseguro e sua decodificação pouco atrativa. A forma de reprodução do poder econômico no interior do Estado e o conflito com os trabalhadores que executam as políticas são algumas dessas querelas nas quais a sociedade civil parece não lhe dar o assento principal, deslocando o foco para o entorno que lhes é cotidiano ${ }^{15}$. 
Diante do exposto, este ensaio indaga sobre a forma como o 'controle social' está sendo feito, especialmente na contemporaneidade, quando a internet entra como mais um elemento que complexifica essa discussão. A problematização transita na dúvida sobre se o 'controle social' se torna mais qualificado no exercício de autonomia e emancipação pela sociedade civil ou se, ao contrário, ajusta-se como nova forma a práticas hegemônicas de controle, tutela e dominação.

Com esse objetivo, coloca-se o foco no exercício do 'controle social' sobre uma dimensão de particular interesse para o tema, consubstanciado no que se pode denominar 'Desempenho das Políticas de Saúde', para além da institucionalidade do SUS, à luz do que vem sendo chamado de webcontrole.

Tal reflexão foi motivada, e tomou como exemplo, o conteúdo trazido pela política de 'Avaliação de Desempenho' na saúde, impulsionada pelo governo federal brasileiro e viabilizada no âmbito da implantação de mecanismos de 'Governo Eletrônico' (https://www.governoeletronico.gov.br), como parte da Estratégia de Governança Digital ('e-government'), com a finalidade de promover acesso às informações, melhorar os serviços públicos digitais e ampliar a participação social.

É pertinente lembrar que uma expressão pública na saúde dessa política foi a criação e aplicação do Índice de Desempenho do Sistema Único de Saúde (IDSUS), cujo objetivo central foi gerar um valor-síntese, numérico, sobre o desempenho do SUS, nas três esferas de gestão, com o propósito de possibilitar a elaboração de uma classificação hierárquica para orientar gestores e a opinião pública sobre os sistemas de saúde.

\section{A medição do desempenho e a avaliação em saúde}

Um objeto de medição pode ser, muitas vezes, de difícil interpretação para a sociedade civil e seus sujeitos. Veja-se, por exemplo, como a literatura de base 'gerencialista' vem desenvolvendo a noção de 'desempenho' e, também, o que a Saúde Pública identifica, rotineiramente, como sendo 'avaliar' em saúde.

É uma tradição na saúde pública, e mesmo sob o paradigma mais recente da saúde coletiva, o uso ('avaliação') dos resultados alcançados pelas organizações. Captar o que se tem chamado de 'desempenho' nos equipamentos de saúde tem se tornado o fim último daqueles que creem nestes mecanismos para avaliar o cumprimento de suas missões. Assim, o debate acerca dos Sistemas de Medição de Desempenho tem sido suscitado para caracterizar as atuações desses serviços, em diferentes contextos e conjunturas ${ }^{16}$.

Para os teóricos da área da administração, um Sistema de Medição de Desempenho Organizacional parece ser uma tendência crescente na administração pública ${ }^{17}$, especialmente por contribuir para o alinhamento dos serviços às estratégias governamentais. Para tanto, a formulação dos indicadores e suas potências para descreverem o que é essencial ao 'desempenho' aparece como tarefa a ser realizada com muita cautela.

Lohman, Fortuin e Wouters ${ }^{18}$ estão entre os autores para os quais um Indicador de Desempenho é uma variável que demonstra quantitativamente a eficácia, ou a eficiência, ou ambas, de parte ou do todo de um processo ou sistema, frente a uma determinada norma ou objetivo. Por esta razão, tal indicador é também chamado de Métrica de Desempenho.

Um 'indicador' ou 'métrica' permite monitorar o desempenho das ações voltadas a materializar as estratégias, criando, assim, um elo entre o planejado e o realizado, relação que envolve estratégia, ação e mensuração. Um Sistema de Mensuração de Desempenho - ou Performance Measurement System (PMS) - pode ser entendido, portanto, como um 'conjunto' dessas métricas quando aplicadas à quantificação da eficiência e à eficácia de ações organizacionais ${ }^{19}$.

A medição do desempenho apresenta 
algumas vantagens. Segundo Atkinson, Waterhouse e Wells ${ }^{20}$, estas podem monitorar a implementação de seus planejamentos e determinar quando eles não estão tendo êxito, além de como melhorá-los. Outros ${ }^{21}$ afirmam que precisam estar alinhadas com as prioridades estratégicas, sob o prisma de 'controle do alinhamento'. A evolução dos Sistemas de Mensuração de Desempenho vem se delineando de modo a acompanhar a forma de operar das organizações que têm concentrado seus processos em formato de 'cadeias' ou em 'redes'. Esta última, muito familiar às práticas da saúde pública e, no Brasil, incorporada na sua racionalidade gerencial, nos últimos $20 \operatorname{anos}^{22}$.

Contudo, as medidas de desempenho apresentam algumas desvantagens. A mais citada relaciona-se com a 'definição de indicadores coerentes com suas práticas', ou seja, que traduzam as dimensões do processo sob avaliação ${ }^{23}$. Outra muito recorrente em empresas com foco no mercado é o abuso de indicadores financeiros como medidas que sumarizam o desempenho. Por isto, cada vez mais medidas não financeiras vêm sendo usadas para caracterizar o desempenho, tais como: participação de mercado, satisfação dos clientes, inovação e desenvolvimento de novos produtos e rotatividade de empregados ${ }^{24-26}$.

Neely ${ }^{27}$ apresenta um rol de princípios para a elaboração de indicadores a serem usados nos Sistemas de Mensuração de Desempenho: a) as métricas ou indicadores devem ser diretamente relacionadas com as estratégias; b) indicadores não financeiros devem ser adotados; c) deve ser reconhecido que indicadores variam por departamentos ou locais; d) deve ser reconhecido que indicadores mudam, assim como as circunstâncias; e) os indicadores devem ser simples e fáceis de usar; f) os indicadores devem oferecer 'feedback' rápido; e g) os indicadores devem ser concebidos de modo a estimular a melhoria contínua, e não apenas como meros monitores.

Em que pese à relevância do pensamento 'gerencialista' para facilitar a captura de processos organizacionais (entendendo-se os serviços de saúde como um tipo de organização), pode-se dizer que suas características não são triviais quando o desempenho é avaliado pelo sujeito comum.

A saúde pública considera tradicionalmente a avaliação como um instrumento gerencial28. Reconhecidamente essencial na tomada de decisões, a avaliação gerencial padece, contudo, de subutilização derivada de uma cultura avaliativa pouco institucionalizada. Nesse contexto, o que esperar da avaliação advinda do 'controle social'? Parece razoável admitir que tende a reproduzir abordagens assentadas na teoria e na prática 'gerencialista', notadamente em um contexto em que o acesso a dados e a variados sistemas de informação em saúde amplia-se de modo formidável, ainda que na perspectiva do webcontrole.

Esse aspecto, relacionado com o rumo que o controle público das políticas de saúde tomará nos próximos anos, e o papel que assumirá o webcontrole nesses processos, apenas reproduzindo práticas de cunho 'gerencialista' ou, opondo-se a elas, criando novas possibilidades avaliativas referenciadas em concepções não gerencialistas, emerge como um desafio de importância estratégica, influenciando também o projeto de Governo Eletrônico e, em última instância, a própria democracia, como base do Estado de Direito.

Não é exagero admitir que uma nova onda de avaliação da sociedade civil sobre as práticas gerenciais emergirá como imperativo das lutas pelo aprofundamento da democracia e da transparência das ações do Estado, seja em qual regime político ou modo de produção for, já que o acesso à informação é elemento central no avanço das forças produtivas. A saúde pública, enquanto campo de conhecimentos e práticas, não poderá esquivar-se disto.

Ademais, é preciso considerar que, para além de uma função administrativa, avaliar é 
uma ação cotidiana que todos os sujeitos realizam diuturnamente em suas vidas, uma vez que valoram e comparam constantemente ${ }^{28}$. Assim, 'avaliação' em sentido lato corresponde ao significado de 'atribuir juízo de valor a algo'29. Nesta perspectiva, deve-se considerar que o denominado 'controle social' é, simultaneamente, sujeito e objeto, pois se, de um lado, tem a atribuição de 'avaliar' os mais diferentes aspectos relacionados com a saúde das populações (é, portanto, sujeito), de outro lado, é, ele próprio, objeto de processos avaliativos variados, nos quais pode ser tomado como um conjunto de informações sobre $o$ passado para guiar a ação futura ${ }^{30,31}$.

\section{Os sistemas de saúde como 'objetos' da avaliação de desempenho}

Os termos 'avaliação' e 'desempenho' são percebidos diferentemente por diversos autores, modelos analíticos e pela sociedade civil. Situação similar ocorre quando se trata da percepção do que sejam 'sistemas de saúde', pois há importantes divergências entre autores e disciplinas científicas. Por esta razão, não é banal, nem simples formalidade, apenas juntar tais termos em uma única expressão ('avaliação - desempenho - sistemas de saúde') e empregá-la em processos comunicativos, sem mais explicações. É, porém, muito frequente que os que fazem uso da expressão 'Avaliação do Desempenho de Sistemas de Saúde' não explicitem os conteúdos que lhe são subjacentes, em seus respectivos contextos analíticos, ainda que suas concepções venham se refinando ao longo do tempo ${ }^{32}$.

Segundo Roemer ${ }^{33}$, 'sistemas de saúde' são estruturas de serviços baseadas em uma combinação de recursos, organização, financiamento e gerenciamento que culminam na prestação de serviços de saúde para a população. Outro autor ${ }^{34}$, afirma que são respostas sociais organizadas deliberadamente para responder às necessidades, demandas e representações 'de saúde' [inserção nossa] das populações, em determinada sociedade, em certo tempo. Em síntese, outros autores ${ }^{35-38}$ dizem que se trata do conjunto de relações políticas, econômicas e institucionais responsáveis pela condução dos processos referentes à saúde de uma dada população.

Quanto aos seus componentes, afirma-se que os sistemas de saúde são constituídos pelos seguintes componentes: a) modelo de atenção; b) financiamento; c) infraestrutura; d) organização; e e) gestão. Uma proposição mais abrangente, outros identificam que os sistemas de saúde dependem de 'componentes' que interagem através de suas 'funções'39.

Por essas razões, ao avaliar sistemas, é necessário estabelecer claramente a diferença entre 'sistemas de saúde' e 'sistemas de serviços e cuidados em saúde'40. Os primeiros são muito mais abrangentes e se referem à saúde em um sentido ampliado, como resultado de uma interação complexa de um conjunto de fatores/ações de diversos sistemas sociais ${ }^{41}$. Contudo, os sistemas de saúde não têm responsabilidades diretas, ou governabilidade, sobre o conjunto das condições sociais, econômicas, culturais e demográficas que afetam a capacidade das pessoas de viverem bem e por muito tempo.

De fato, em estudos que buscam avaliar os sistemas de saúde, o foco tende a recair sobre os 'sistemas de serviços e cuidados', o que faz com que apresentem grande proximidade com as análises de políticas e com os estudos de serviços de saúde. Isto ocorre porque esses estudos usam praticamente os mesmos recursos disciplinares, como a epidemiologia, a economia, as ciências sociais e humanas, e a administração.

Essa interação, em busca de uma abordagem interdisciplinar, é positiva e contribui para o conhecimento dos sistemas de saúde. No entanto, há necessidade de distingui-los. As análises de políticas de saúde priorizam as relações políticas e institucionais entre os atores da área de saúde, enquanto as 
avaliações de serviços de saúde priorizam o conhecimento dos efeitos das ações das instituições prestadoras de serviços de saúde sobre as condições de vida e saúde das populações.

Estes aspectos devem ser levados em consideração ao se avaliar sistemas de saúde, pois esse propósito implica em enfrentar a dificuldade operacional relacionada com a definição de 'desempenho', tendo por referência 'sistemas de saúde'. Basta pensar que os sistemas de saúde lidam com diversas organizações, cuja maioria tem obrigações centradas nos usuários, com a produção de múltiplos 'produtos'.

Os sistemas de saúde têm uma orientação fortemente focada no processo, e sua produção frequentemente é confundida com a de outros coprodutores de saúde. Ainda, os seus produtos são entrelaçados por causalidades desconhecidas, por isso, definir o que é 'desempenho' neste contexto constitui-se em algo fugidio e bastante desafiador em termos metodológicos, uma vez que há, frequentemente, incoporação e exclusão de unidades de serviços, implicando em mudanças que podem alterar, em maior ou menor grau, a estrutura e a dinâmica dos sistemas.

Com os problemas enfrentados pelo SUS no seu desenvolvimento, a experiência da gestão brasileira tem advogado pela tomada de decisão 'mais objetiva', abrindo espaço para firmar a 'nova administração pública' focada em resultados ${ }^{42}$, envernizando sua retórica e alinhando-a aos princípios da universalidade, integralidade e equidade ${ }^{\mathbf{4 3}}$.

Assim, o desempenho tem se tornado uma preocupação central dos tomadores de decisão de políticas públicas e gerentes, no período histórico do final do século XX e nas décadas iniciais do século XXI. A lógica do 'desempenho' tem sido a 'palavra de ordem' das abordagens de gerenciamento de serviços públicos (especialmente, em serviços de saúde) ${ }^{\mathbf{4 4}}$.

Mesmo um dos poucos consensos da literatura afirmando que os 'resultados' esperados de quaisquer sistemas de saúde são a melhoria das condições de saúde de seus cidadãos, a capacidade de resposta às necessidades individuais e preferência dos usuários, a proteção financeira oferecida pelo sistema de saúde e a produtividade da utilização dos recursos de saúde ${ }^{45}$, a gestão federal insiste no uso do desempenho focado, de modo evidentemente restrito, na produtividade como mecanismo de perdas e ganhos de incentivos.

Esse é o caso do Programa de Melhoria da Avaliação da Qualidade na Atenção Básica (PMAQ-AB), cujo modelo de avaliação de desempenho coloca seu foco avaliativo em nível 'micro' (equipes de saúde), em apenas um nível de atenção (atenção básica à saúde) e, com uma matriz metodológica de inspiração 'donabediana', utiliza indicadores de estrutura, processo e satisfação do usuário ${ }^{46}$.

Outro modelo, criado em 2012, foi o IDSUS, cuja proposta avaliativa implica analisar o desempenho a partir do cruzamento de indicadores simples e compostos aplicados aos entes federativos: Municípios (organizados ou não em regiões de saúde), Estados e União. O IDSUS coloca seu foco no 'desempenho' e busca operacionalizar os quesitos de 'eficiência' e de 'acesso aos serviços de saúde' nos diversos níveis do sistema e em alguns elementos de determinação social da saúde ${ }^{47}$. Enfatiza-se a produtividade, a qual serve de parâmetro para a alocação de incentivos financeiros para sistemas regionais.

Tanto o IDSUS quanto o PMAQ-AB foram desenvolvidos sem levar em conta a experiência do Programa de Avaliação de Desempenho para Sistemas de Saúde (Proadess), desenvolvido a partir de pesquisas do Instituto de Comunicação e Informação em Ciência e Tecnologia (Icict), da Fundação Oswaldo Cruz (Fiocruz), baseando-se no marco teórico das desigualdades em saúde ${ }^{\mathbf{4 8}}$.

Não obstante o valor que se possa atribuir a essas iniciativas avaliativas com origem na gestão nacional do SUS, o fato crucial relativo a esses processos de avaliação mencionados é que a essência do que se toma por ‘desempenho’ é questionável, especialmente 
se o questionamento não se restringe aos métodos e às técnicas empregados, mas é dirigido, epistemologicamente, ao objeto (o quê) esses processos avaliativos, com os instrumentos empregados, estão se propondo a medir, com vistas à avaliação.

Cabe enfatizar que as características básicas dos processos de avaliação do desempenho não estão explicitadas nas formulações desses processos avaliativos, deduzindo-se que seu significado é tácito, não requerendo explicitação. Porém, o próprio sentido de 'desempenho' não está suficientemente esclarecido como expressão dos indicadores utilizados em ambos os processos. A principal consequência dessa indefinição é a possibilidade de enviesamentos metodológicos de vários tipos em estudos e análises sobre 'desempenho', a partir desses processos avaliativos, com possibilidades de lhes comprometer o propósito que os enseja, isto é, prestarem-se a efetivamente avaliar algo.

Outro aspecto deve ser acrescentado às considerações sobre esse tipo de avaliação enquanto política pública: a polissemia da palavra 'resultado'. A tendência, na denominada 'gestão por resultados', é compreender os 'processos' de produção de ações e serviços, tangíveis de modo imediato, como 'resultados' desses sistemas. Uma dificuldade para esta concepção e abordagem avaliativa é que sistemas de saúde geram resultados tangíveis, portanto mensuráveis, mas, na maior parte das vezes, resultados intangíveis e, portanto, não mensuráveis imediatamente - e, por vezes, nem mediatamente.

Em face a essa problemática sobre o desempenho de sistemas de saúde, é bastante razoável que se considere que a apreciação de tais resultados é dúbia, quando não completamente equivocada. A apreensão do que é 'resultado' de um determinado 'sistema' - portanto, a ele atribuível é praticamente inseparável dos efeitos concomitantes de outras políticas às quais o 'resultado' também pode ser atribuído, no todo ou em parte. Assim, admitir que um certo 'resultado' decorra (apenas) do 'desempenho' de um 'sistema' e, portanto, atribuir ao 'sistema' o estatuto de responsabilidade por determinado efeito será sempre uma afirmação, pelo menos, questionável.

Por isso, é necessário cautela também ao se falar sobre o 'controle social sobre o desempenho de sistemas de saúde'. Especialmente, em termos do 'conteúdo'. Muitos conceitos são difusos e polissêmicos, e precisariam ser bem esclarecidos ou consensuados socialmente. O desempenho dos sistemas de saúde como 'objetos' de controle parece requerer da sociedade civil muito mais qualidade na disseminação e no processamento da informação do que no controle de outros objetos e produtos. Dificuldade adicional pode decorrer, em determinados contextos, do fato de que sujeitos interessados em realizar o 'controle social' sobre o 'desempenho' de um dado 'sistema de saúde' se utilizam da virtualidade como forma cotidiana de informação.

\section{O sujeito, a participação e a forma virtual}

Um argumento bastante repetido, relacionado com a busca incessante por resultados (e, consequentemente, pelo desempenho), advém do princípio da participação dos cidadãos no controle (externo) do Estado, por meio da apreciação do desempenho da administração pública ${ }^{49}$.

Também conhecida na ciência política como 'accountability vertical'50, a incorporação desse tipo de 'controle social' e de responsabilização da administração pública pelo desempenho aparece como uma promessa de substituição de um modelo no qual impera o controle burocrático para outro no qual se estabelece o controle 'a posteriori' de resultados da ação governamental, e no qual a sociedade participaria da definição de suas metas e dos indicadores de desempenho, assim como da avaliação direta dos bens e serviços públicos ${ }^{51}$. 
É a partir dessa perspectiva que o 'gerencialismo' pretende preencher um vácuo teórico e prático, captando as principais tendências presentes na opinião pública (webcontrole), entre as quais se destacam o controle dos gastos públicos e a demanda por melhor qualidade dos serviços públicos, assim como promover o exercício do aprendizado social com a esfera pública, criando uma 'nova cultura cívica', que congregue políticos, funcionários e cidadãos ${ }^{52}$.

Contudo, resta o questionamento sobre as formas com que essa opinião pública pode controlar as ações do Estado, mesmo em contextos de aparente democracia, ou democracia deformada, uma vez que é notória a assimetria entre o poder de agentes econômicos e de organizações comunitárias, para ficar em apenas um exemplo sobre as dificuldades e desafios postos aos interessados em radicalizar as experiências de aprofundamento do 'controle social' no Estado contemporâneo.

No período histórico da primeira metade do século XXI, a constituição dos sujeitos portadores de direitos postula a diferença como compatível à igualdade, bem como suas implicações mais imediatas, que dizem respeito a como conciliar o individualismo que fundamenta a noção moderna de cidadania com as demandas crescentes por direitos de minorias, ou direitos coletivos, como é o caso da saúde ${ }^{53}$.

Nos argumentos do 'gerencialismo', a cidadania está relacionada com o valor de accountability ${ }^{50}$. Isso requereria a participação ativa da sociedade civil, desde a escolha dos dirigentes até o momento da elaboração das políticas, e na avaliação dos serviços públicos. Entretanto, o ato de controlar as políticas públicas parece ser realizado por um tipo de sujeito 'consumidor', que é, no mais das vezes, um cidadão passivo.

Há uma convergência da literatura sobre os objetivos da avaliação e sua relação com a criação e o fortalecimento de mecanismos de accountability na administração pública. Não por acaso, a ideia de que quanto mais perto o cidadão estiver do poder de decisão com relação às políticas públicas, melhor será a qualidade da prestação do serviço e, de fundamental importância, maior será o grau de accountability ${ }^{51,53}$.

Constata-se, contudo, uma escassez de análises empíricas ou pesquisas sistemáticas acerca das relações causais e das condições que estruturam essa suposta relação entre avaliação do desempenho de políticas públicas e a promoção de maior transparência e criação de mecanismos de accountability ${ }^{51}$.

Admitindo-se o sujeito contemporâneo como o sujeito que parece mais afastado da sua integração com os seus ou da sua capacidade de gerar mudança, é que a questão do controle das instituições do Estado - incluindo as políticas públicas - pelos sujeitos da sociedade civil ('controle social') se torna crítica.

A menção à ideia de 'sujeito' remete à imagem Iluminista do indivíduo identificado com a Razão, afastando fantasmas e explicações metafísicas, cuja consciência é a presença no indivíduo (ou em um grupo de indivíduos) de representações de si que contenham juízos de valor morais sobre as condutas desse indivíduo ou grupo ${ }^{54}$.

Contudo, sob o rótulo da individualização, a importância da ideia de sujeito para uma ação coletiva vem se reconfigurando, tendo implicações profundas no que se entende por accountability. Ser sujeito na contemporaneidade é esta chamada de si para si, esta palavra dirigida a si mesmo, que só aparece quando a ação humana é capaz de criar um mundo inteiramente artificial, como as redes de comunicação, por exemplo, que fazem desaparecer gradualmente os sujeitos nas obras da atividade coletiva ${ }^{\mathbf{5 3}}$.

Nessa situação, a interface entre sujeitos e instituições políticas, que alguns autores denominam 'nova cidadania' ou 'cidadania de sujeitos em redes', é uma realidade palpável e em expansão na assim denominada 'Sociedade da Informação', com destaque para a participação, predominantemente opinativa, estimulada por redes virtuais como Twitter, Facebook e outras ${ }^{55,56}$. 
Esse tipo de participação tem ampliado a visibilidade pública dos eventos políticos, com grande repercussão através das mídias, mas sem garantia de continuidade de engajamento mobilizatório, devido à fugacidade do seu comprometimento político ${ }^{56}$.

\section{À guisa de conclusão}

Para além da ideia de Governo Eletrônico ('e-government'), consubstanciada em iniciativas como consultas públicas, ouvidorias digitais, acompanhamentos de protocolos de processos administrativo-legais, entre outros aspectos que buscam garantir o 'controle social' nos serviços públicos, cabe indagar como a sociedade civil pode massivamente participar, sem necessariamente se institucionalizar, compondo como parte de estratégias que tenham como fim o aprofundamento e a radicalização da democracia.

Nessa perspectiva, sob a égide da individualização, a radicalidade da ideia de participação deve ser repensada, buscando-se aprofundar as possibilidades de controle de políticas públicas pela sociedade civil, a partir da elaboração da opinião coletiva oriunda da captura e do processamento das percepções individuais disponibilizadas em todos os sítios eletrônicos na 'web', a rede mundial de computadores.

O caso concreto da política de avaliação de desempenho no SUS, que se materializa pelas iniciativas IDSUS e PMAQ-AB, é exemplar a esse respeito, na medida em que expressa toda a complexidade inerente ao processo de mensuração, que transita entre o objeto, o conteúdo e a forma. Neste contexto, a opinião coletiva pode facilmente servir de ratificadora do que está sendo proposto sem que, necessariamente, seja captada e processada criticamente a essência do que está sendo posto a julgamento público.

Conferir a esse 'controle público' a qualidade que se espera dele, nos marcos do webcontrole, implica admitir a emergência e a criação de outros significados, mais desafiadores, do que se pode entender como 'controlar a administração pública'. Implica também, portanto, promover e conviver com outros padrões, inovadores por certo, de gestão participativa da 'res publica', ainda que em um tempo histórico de hegemonia do capital financeirizado, a tutelar o Estado, deformando o significado mais profundo da democracia. 


\section{Referências}

1. Carvalho AI. Conselhos de Saúde no Brasil: participação cidadã e controle social. Rio de Janeiro: FASE; IBAN; 1995.

2. Berger PL. Perspectivas sociológicas: uma visão humanística. 29. ed. Petrópolis: Vozes; 2007.

3. Martins PC, Cotta RMM, Mendes F et al. Conselhos de saúde e a participação social no Brasil: matizes da utopia. Physis. 2008;18(1):105-121.

4. Secchi L. Modelos organizacionais e reformas da administração pública. Rev. Admin. Pública. 2009; 43(2):347-369.

5. Paula APP. Um modelo de gestão em crise. In: Paula APP. Por uma nova gestão pública: limites e potencialidades da experiência contemporânea. Rio de Janeiro: FGV; 2005. p. 81-102.

6. Bobbio N. Estado governo e sociedade: por uma teoria geral da política. Rio de Janeiro: Paz e Terra; 1987.

7. Rothberg D. Por uma agenda de pesquisa em democracia eletrônica. Opin. Pública. 2008; 14(1):149-172.

8. Castiel LD, Vasconcellos-Silva PR. Precariedades do excesso: informação e comunicação em saúde coletiva. Rio de Janeiro: Fiocruz, 2006.

9. Dias FN. Os sistemas de conhecimento patológico e a nova ordem. Lisboa: Instituto Piaget; 2013.

10. Ricouer P. Hermenêutica e ideologias. 3. ed. Petrópolis: Vozes; 2013.

11. Elia L. O conceito de sujeito. 3. ed. Rio de Janeiro: Zahar; 2004.

12. Touraine A. Igualdade e diversidade: o sujeito democrático. Bauru: EDUSC; 1998.

13. Pires V. O controle social da administração pública: entre o político e o econômico. In: Guedes AM, Fon- seca F, organizadores. Controle social da administração pública: cenário, avanços e dilemas no Brasil. São Paulo: Cultura Acadêmica; Rio de Janeiro: FGV; 2007. p. 17-42.

14. Beck U. Ciência para além da verdade e do esclarecimento? Reflexividade e crítica do desenvolvimento científico. In: Beck U. Sociedade de Risco. Rumo a uma outra modernidade. São Paulo: 34; 2010. p. 235-247.

15. Arato A. Representação, soberania popular e accountability. Lua Nova. 2002; 55(56):85-103.

16. Motta PR. Modernização da administração pública brasileira nos últimos 40 anos. Rev. Admin. Pública. 2007; 41(esp):87-96.

17. Kaplan RS, Norton DP. A estratégia em ação: balanced scorecard. 13. ed. Rio de Janeiro: Campus; 1997.

18. Lohman C, Fortuin L, Wouters M. Designing a performance measurement system: a case study. Eur. J. Oper. Res. 2004; 156(2):267-286.

19. Neely A, Gregory M, Platts K. Performance measurement system design - a literature review and research agenda. Int. J. Oper. Prod. Manag. 2005; 25(12):1228-1263.

20. Atkinson A, Waterhouse J, Wells R. Stakeholder approach to strategic performance measurement. Sloan Manag. Review. 1997; 38(3):25-37.

21. Bititci U, Tuner T, Begemann C. Dynamics of performance measurement systems. Int. J. Oper. Prod. Manag. 2000; 20(6):692-704.

22. Mendes EV. Redes de atenção à saúde. Ciênc. Saúde Colet. 2010; 15(5):2297-2305.

23. Busanelo EC. Um panorama dos estudos sobre avaliação de desempenho logístico: indicadores e sistemas de mensuração. In: Anais XXXV Encontro da ANPAD. Rio de Janeiro: Anpad; 2011 [acesso em 
2017 jan 31]. Disponível em: http://www.anpad.org. br/admin/pdf/GOL2971.pdf.

24. Verbeeten F, Boons A. Strategic priorities, performance measures and performance: an empirical analysis in dutch firms. Eur. Manag. J. 2009; 27:113128.

25. Fitzgerald L, Johnston R, Brignall S. Performance measurement in service business. London: CIMA, 1991.

26. Meirelles DS. O conceito de serviço. Rev. Econ. Política. 2006; 26(1):119-136.

27. Neely A. The performance measurement revolution: why now and what next? Int. J. Oper. Prod. Manag. 1999; 19(2):205-228.

28. Tanaka OY, Tamaki EM. O papel da avaliação para a tomada de decisão na gestão de serviços de saúde. Ciênc. Saúde Colet. 2012; 17(4):821-828.

29. Aguilar MJ, Ander-Egg E. Avaliação de serviços e programas sociais. Petrópolis: Vozes; 1994.

30. Arnold M. Evaluation: a parallel process to planning. In: Arnold M. Administering health systems: issues and perspectives. Chicago: Aldine; 1971.

31. Oliveira ABR, Silva UB, Bruni AL. Gerencialismo e desafios contemporâneos da gestão dos custos públicos no Brasil. Rev. Estud. Contáb. 2012; 3(5):6382.

32. Hoffman S, Røttingen JA, Bennett S, et al. Background paper on conceptual issues related to health systems research to inform a WHO global strategy on health systems research. Geneva: WHO; 2012 [acesso em 2016 dez 16]. Disponível em: http:// www.who.int/alliance-hpsr/alliancehpsr_backgroundpaper hsrstratl.pdf.

33. Roemer M. National Health Systems of the World. Oxford: Oxford University Press; 1991.

34. Mendes EV. Os sistemas de serviços de saúde: o que os gestores deveriam saber sobre essas organizações complexas. Fortaleza: Escola de Saúde Pública do Ceará; 2002.

35. Lobato LVC, Giovanella L. Sistemas de saúde: origem, componentes e dinâmica. In: Giovanella L, Escorel S, Lobato LVC, et al. Políticas e sistema de saúde no Brasil. 2. ed. Rio de Janeiro: Fiocruz, 2012. p. 89-120.

36. Starfield B. Atenção primária: equilíbrio entre necessidades de saúde, serviços e tecnologia. Brasília, DF: Ministério da Saúde; 2002.

37. World Health Organization. Strengthening health systems to improve health outcomes. Geneva: WHO; 2007.

38. Conill EM. Sistemas comparados de saúde. In: Campos GWS, Minayo MCS, Akerman M, et al. organizadores. Tratado de saúde coletiva. São Paulo: Hucitec; Rio de Janeiro: Fiocruz; 2006. p. 563-613.

39. Kleczkowski B, Roemer M, Werff A. National health systems and their orientation towards health for all: guidance for policy-making [internet]. Geneva: WHO; 1984 [acesso em 2013 fev 17]. Disponível em: http://apps.who.int/iris/bitstream/10665/41638/1/ WHO_PHP_77.pdf.

40. Mendes EV. As redes de atenção à saúde. Brasília, DF: Organização Pan Americana da Saúde; 2011.

41. Lévesque JF, Bergeron P. De l'individuel au collectif: une vision décloisonnée de la santé publique et des soins. Rupture - Rev. Transdiscipl. Santé. 2003; 9(2):73-89.

42. Garces A, Silveira JP. Gestão pública orientada por resultados no Brasil. Rev. do Serv. Público. 2002; 53(4):53-77.

43. Tanaka OY, Tamaki E, Felisberto E. Os desafios da avaliação na gestão do SUS. Ciênc. Saúde Colet. 2012; 17(4):818-818.

44. Exworthy M. The performance paradigm in the En- 
glish NHS: potential, pitfalls, and prospects. Eurohealth. 2010; 16(3):16-19.

45. Smith PC, Mossialos E, Papanicolas I, et al. Introduction. In: Smith PC, Mossialos E, Papanicolas I, et al. Performance measerument for health system improvement: Experiences, challenges and prospects. Cambridge: European Observatory; 2012 [acesso em 2012 mar 30]. Disponível em: http://www. euro.who.int/_data/assets/pdf_file/0007/135970/ E94887_Part_I.pdf.

46. Brasil. Portaria no 1.654, de 19 de julho de 2011. Institui, no âmbito do Sistema Único de Saúde, o Programa Nacional de Melhoria do Acesso e da Qualidade da Atenção Básica (PMAQ-AB) e o Incentivo Financeiro do PMAQ-AB, denominado Componente de Qualidade do Piso de Atenção Básica Variável - PAB Variável. Diário Oficial da União. 19 jul. 2011.

47. Brasil. Ministério da Saúde. PROADESS - Avaliação de Desempenho do Sistema de Saúde Brasileiro: indicadores para monitoramento. Relatório final 642 (versão para discussão). Laboratório de Informações em Saúde - LIS, Instituto de Comunicação e Informação em Ciência e Tecnologia - ICICT. Rio de Janeiro: Fundação Oswaldo Cruz; 2011.

48. Brasil. Ministério da Saúde. IDSUS: Índice de Desempenho do Sistema Único de Saúde. Brasília, DF: MS; 2011.

49. Viacava F, Ugá MAD, Porto S, et al. Avaliação de desempenho de sistemas de saúde: um modelo de aná- lise. Ciênc. Saúde Colet. 2012; 17(4):921-934.

50. Andrade LOM. Inteligência de governança para apoio à tomada de decisão. Ciênc. Saúde Colet. 2012; 17(4):829-832.

51. Guedes AM, Fonseca F, organizadores. Controle social da administração pública: cenário, avanços e dilemas no Brasil. São Paulo: Cultura Acadêmica; Rio de Janeiro: FGV; 2007.

52. O'Donnell G. Accountability horizontal e as novas poliarquias. Lua Nova. 1988; 44:27-54.

53. Abrucio FL. O impacto do modelo gerencial na administração pública: um breve estudo sobre a experiência internacional recente. Brasília, DF: Enap; 1997.

54. Reis EP. Sociologia política e processos macro-históricos. Sociologias. 2015; 17(38):18-43.

55. Touraine A. Pensar de outro modo. Lisboa: Instituto Piaget; 2007.

56. Scherer-Warren I. Desafios para uma sociologia política brasileira: os elos entre movimentos e instituições. Sociologias. 2015; 17(38):44-62.

\footnotetext{
Recebido em 11/04/2018

Aprovado em 08/07/2018

Conflito de interesses: inexistente
}

Suporte financeiro: não houve 